\title{
IDENTIFICAÇÃO DAS ÁREAS DE PRESERVAÇÃo PERMANENTE NO MUNICÍPIO DE ALEGRE UTILIZANDO GEOTECNOLOGIA
}

\author{
Fernando Coelho Eugenio ${ }^{1}$, Alexandre Rosa dos Santos ${ }^{2}$, Franciane Lousada Rubini de Oliveria Louzada ${ }^{3}$, \\ Leonardo Bergantini Pimentel ${ }^{4}$, Janine Varanda Moulin ${ }^{5}$
}

(recebido: 1 de março de 2010; aceito: 22 de agosto de 2011)

\begin{abstract}
RESUMO: Devido à necessidade de estudos atuais sobre as Áreas de Preservação Permanentes (APPs) para o município de AlegreES, propõem-se, neste estudo, demonstrar como a utilização de Geotecnologias pode ajudar de forma eficaz o mapeamento dessas áreas, auxiliando no entendimento das áreas a serem preservadas no município. O estudo foi realizado em todo o município de Alegre, ES, com o objetivo de elaborar mapas analógicos e digitais do município, com o auxílio de Geotecnologias; delimitar as Áreas de Preservação Permanente na ótica da Legislação Ambiental e ressaltar a importância de identificar as áreas de forma automática para que se possam implantar projetos ambientais que visem a promover ações em busca de um relacionamento sustentável entre homem e ambiente de forma mais eficiente. O município de Alegre possui uma área de $336,39 \mathrm{~km}^{2}$ de APPs totais $(43,50 \%$ da área total do município). A metodologia adotada para delimitação automática das APPs foi eficiente, revelando que as mesmas, ao redor de nascentes (buffer de $50 \mathrm{~m}$ ), nas encostas com declividade superior a 45 graus, topo de morro (terço superior de morros) e margens dos cursos d'água (buffer de $30 \mathrm{~m}$ ) representaram respectivamente $9,86 \mathrm{~km}^{2}(1,27 \%), 8,99 \mathrm{~km}^{2}(1,16 \%), 237,35 \mathrm{~km}^{2}(30,69 \%)$ e $95,11 \mathrm{~km}^{2}(12,30 \%)$ da área total do município.
\end{abstract}

Palavras-chave: APPs, sistema de informação geográfica, legislação ambiental.

\section{IDENTIFICATION OF PERMANENT PRESERVATION AREAS IN ALEGRE-ES BY USING GEOTECHNOLOGY}

\begin{abstract}
Due to the need of current studies on the Permanent Preservation Areas (APPS) for the county of Alegre - ES, it is proposed in this study to demonstrate how the use of Geotechnologies can help in an effective way to map those areas, helping to understand the areas to be preserved in the county. The study was accomplished in the whole county of Alegre - ES which objectives were: a) to elaborate analogical and digital maps of the county, with the aid of Geotechnologies; b) to delimit the Areas of Permanent Preservation in the optics of the Environmental Legislation and c) to emphasize the importance of identifying the areas in an automatic way so that it can implant environmental projects that seek to promote actions in search of a maintainable relationship between man and environment in a more efficient way. The county of Alegre has an area of $336,39 \mathrm{~km}^{2}$ of $\mathrm{APPs}(43,50 \%$ of the total area of the county). The methodology for automatic delimitation of APPs was efficient, indicating that the same, around of spring (buffer of $50 \mathrm{~m}$ ), in the hillsides with steepness superior to 45 degrees, hill top (superior third of hills) and margins of the courses of water (buffer of $30 \mathrm{~m}$ ) they acted respectively $9,86 \mathrm{~km}^{2}(1,27 \%), 8,99 \mathrm{~km}^{2}(1,16 \%), 237,35 \mathrm{~km}^{2}(30,69 \%)$ and $95,11 \mathrm{~km}^{2}$ $(12,30 \%)$ of the total area of the county.
\end{abstract}

Key words: APPs, system of geographical information, environmental legislation.

\section{INTRODUÇÃO}

Os problemas relacionados ao ambiente e seu futuro vêm sendo abordados constantemente visando à necessidade de se preservar os recursos naturais como um todo, pois estes são as riquezas básicas de uma nação e não se pode compreender que o seu desenvolvimento e progresso sejam obtidos à custa de sua dilapidação ou do seu mau uso (BERTONI; LOMBARDI NETO, citados por LOUZADA, 2008).

As Áreas de Preservação Permanentes (APPs) atualmente estão submetidas à intensa degradação, em

\footnotetext{
${ }^{1}$ Graduando em Engenharia Florestal - Centro de Ciências Agrárias/CCA - Universidade Federal do Espírito Santo/UFES - Alegre, ES - $29500-000$ coelho.fernando@yahoo.com.br

${ }^{2}$ Agrônomo, Professor Dr. em Engenharia Agrícola - Departamento de Engenharia Rural - Centro Agropecuário - Universidade Federal do Espírito Santo Alto Universitário, s/n - Cx. P. 16 - 29500-000 - Alegre, ES - mundogeomatica@yahoo.com.br

${ }^{3}$ Bióloga, Mestre em Ciências Florestais - Departamento de Engenharia Florestal - Centro de Ciências Agrárias - Universidade Federal do Espírito Santo/UFES - Av. Gov. Lindemberg, no 316, Centro - 29.550-000 - Jerônimo Monteiro, ES - francianelouzada@yahoo.com.br

${ }^{4}$ Engenheiro Florestal, Mestrando em Ciências Florestais - Núcleo de Estudos e de Difusão de Tecnologia em Floresta, Recursos Hídricos e Agricultura Sustentável/Nedtec - Centro de Ciências Agrárias - Universidade Federal do Espírito Santo - Av. Governador Lindenberg, s/n, Centro - 29550-000 Jeronimo Monteiro, ES - lbpimentel@yahoo.com.br

${ }^{5}$ Secretaria de Desenvolvimento Sustentável - Prefeitura Municipal de Alegre - 29500-000 - Alegre, ES - semdes@alegre.es.gov.br
}

Cerne, Lavras, v. 17, n. 4, p. 563-571, out./dez. 2011 
razão da intensificação das pressões antrópicas sobre o ambiente. Dessa forma, observa-se um processo de substituição das paisagens naturais por outros usos e ocupações do solo e a conversão das áreas com cobertura florestal em fragmentos florestais, causando problemas ambientais e, em muitos casos, afetando a disponibilidade de recursos naturais importantes à vida (ARES, 2006).

O Código Florestal Brasileiro (BRASIL, 2002) relata que as APPs são fundamentais para a manutenção da vegetação de determinadas áreas com o objetivo de manter inalterado o uso do solo, que deve estar coberto pela vegetação original. Em decorrência das dimensões continentais de alguns países, torna-se indispensável a representação e caracterização das APPs em mapas pois é importante para o planejamento territorial, fiscalização e ações de campo de âmbito local, regional ou nacional.

As metodologias que utilizam a Geotecnologia como ferramenta principal vem se destacando, sendo a alternativa mais viável para se reduzir significativamente o tempo gasto com o mapeamento das áreas a serem protegidas e, por consequência, agilizar o período hábil de fiscalização do cumprimento das leis pertinentes à legislação.

Um dos empecilhos para o monitoramento das APPs é sobre o ponto de vista técnico, pois, se faz necessário o envolvimento de profissionais especializados e o uso de dados altamente precisos da área de estudo. Tais dados geralmente são disponibilizados em uma escala muito pequena e, por consequência, possuem pouca riqueza de detalhes. Contudo, a utilização de equipamentos e o desenvolvimento de sofisticados algoritmos e a sua incorporação ao conjunto de funções das Geotecnologias, permite o processamento rápido e eficiente dos dados necessários para a caracterização das variáveis morfométricas do terreno (OLIVEIRA, 2002).

A Geotecnologia adequa-se perfeitamente à abordagem territorial na medida em que permite efetuar a distribuição espacial dos dados, a visualização de suas relações espaciais, a detecção de processos de concentração e de dispersão de fluxos e contrafluxos, bem como a identificação da série histórica dos dados (PINA, citado por LOUZADA et al., 2009a).

Dentro deste contexto, o presente trabalho propôs demonstrar como a Geotecnologia pode ajudar nos estudos das áreas de preservação permanente, no que confere a sua identificação e delimitação automática, o que auxiliará no futuro o entendimento dos processos de ocupação da terra.

Cerne, Lavras, v. 17, n. 4, p. 563-571, out./dez. 2011
Sendo assim, neste trabalho, objetivou-se, principalmente, delimitar as Áreas de Preservação Permanente (faixa marginal, topo de morro, nascentes e encostas) na ótica da Legislação Ambiental vigente.

\section{MATERIAL E MÉTODOS}

\subsection{Aspectos físicos da área de estudo}

A área de estudo é o município de Alegre, extremo Sul do Estado do Espírito Santo, Brasil, localiza-se entre as latitudes $20^{\circ} 31^{\prime}$ e $20^{\circ} 55^{\prime} \mathrm{Sul}$ e longitudes $41^{\circ} 21$ e $41^{\circ}$ 39' Oeste de Greewinch, com uma área de $773,40 \mathrm{~km}^{2}$ (Figura 1).

O clima da região, segundo a classificação de Koppen, é Cwa, caracterizado pelo inverno seco e o verão chuvoso. De maneira geral, a topografia possui relevo bastante acidentado, intercalada por reduzidas áreas planas. Basicamente, estão estabelecidas na área, as culturas de subsistência, café e, predominantemente, as pastagens, além dos remanescentes florestais nativos localizados principalmente nos topos dos morros.

\subsection{Desenvolvimento do Modelo Digital de Elevação Hidrologicamente Consistente}

Os dados utilizados para geração do Modelo Digital de Elevação Hidrologicamente Consistente (MDEHC) foram as curvas de nível e a rede hidrográfica, ambas na escala de 1:35.000 e cedidas pelo Instituto Estadual do Meio Ambiente (IEMA), adotando-se a exatidão cartográfica de $0,143 \mathrm{~mm}$. Assim, para determinar a menor dimensão no terreno, representada no mapa, ou seja, a resolução espacial das células do MDEHC, multiplicouse a exatidão cartográfica pelo fator de escala, que correspondeu a 5 metros.

Determinada a dimensão da célula de saída e de posse dos referidos dados, a geração do MDEHC para o município de Alegre foi realizada utilizando o algoritmo de interpolação TOPO TO RASTER, disponível no módulo Arc Toolbox do programa ArcGIS 9.3. As operações necessárias para a geração do MDEHC por meio desse algoritmo, exigiram a orientação dos arcos da rede hidrográfica no sentido do escoamento e o ajuste da altimetria à hidrografia.

Em seguida, foram realizadas operações de pósprocessamento com a finalidade de identificar e eliminar a ocorrência de imperfeições (depressões espúrias) no MDHEC e para criação de uma calha ao longo da rede hidrográfica, objetivando garantir a convergência do 


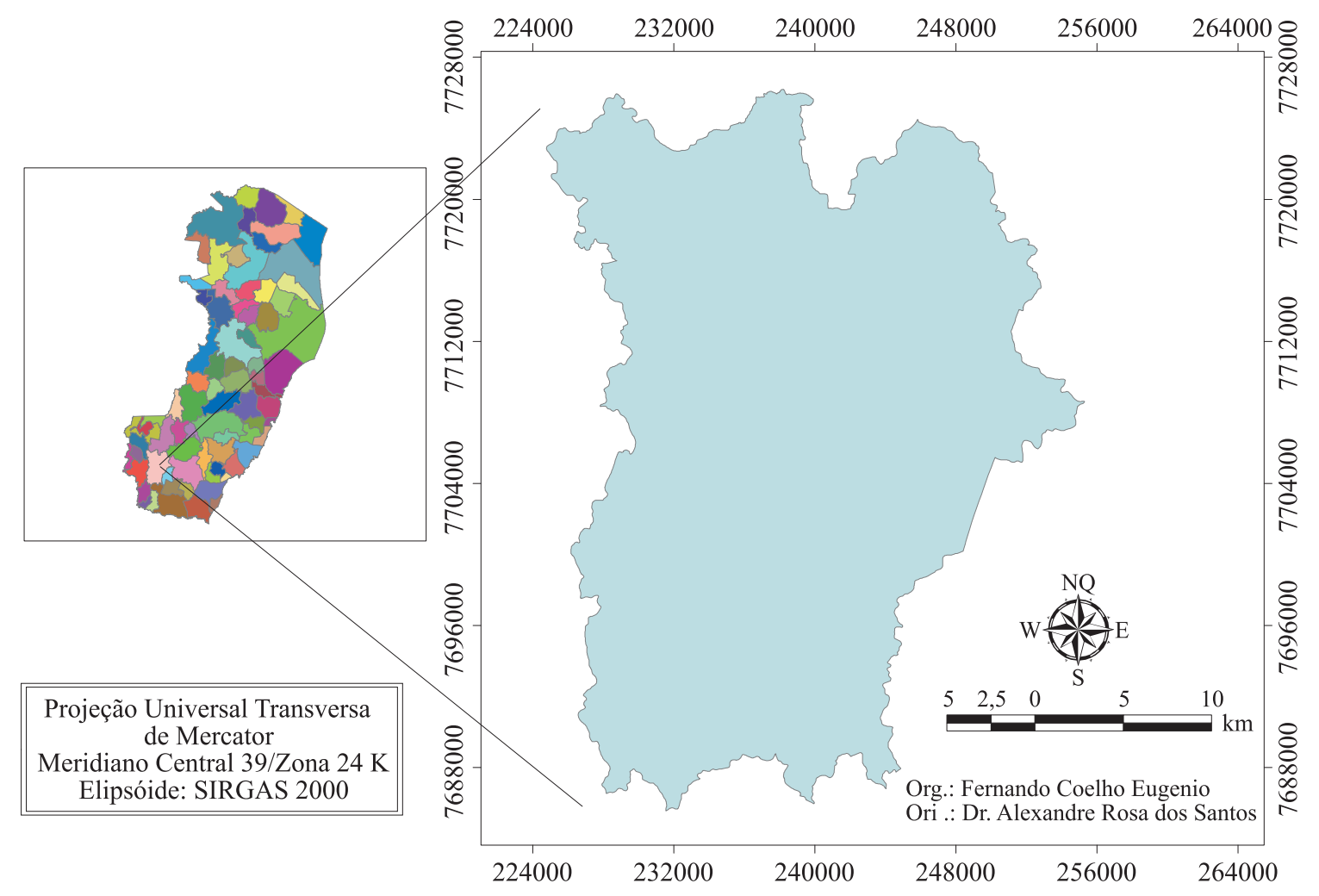

Figura 1 - Localização da área de estudo, município de Alegre, Espírito Santo.

Figure 1 - Location of the study area, county of Alegre, Espirito Santo.

escoamento superficial até a foz da hidrografia. De acordo com Garcia e Camarasa (1999) e Tribe (1992), essas imperfeições são muito frequentes nos MDEs e derivam-se de erros presentes nos dados de entrada ou introduzidos no processo de interpolação. As falsas depressões constituem um problema na geração de modelos de predição do escoamento, pois interrompem o escoamento superficial. Devem, portanto, ser removidas para se ter um MDE consistente sob o ponto de vista hidrológico. Para o preenchimento dessas imperfeições utilizou-se o comando FILL, disponível no módulo Arc Toolbox do programa ArcGIS 9.3.

\subsection{Delimitação das APPs}

De posse dos processamentos realizados nas etapas anteriores, iniciou-se o mapeamento automático das APPs da área de estudo, considerando a faixa marginal dos rios, ao redor das nascentes, nos topo de morros e montanhas (terço superior) e encostas com declividades acima de 45 graus, baseando-se nos critérios estabelecidos pela legislação, Resolução do CONAMA n³03/2002 (CONSELHO NACIONAL DO MEIO AMBIENTE - CONAMA, 2002), a qual dispõe sobre parâmetros, definições e limites das APPs.

\subsubsection{Delimitação das APPs em topo de morro}

O topo de morro, de acordo com a mesma resolução, quando há ocorrência de dois ou mais morros ou montanhas cujos cumes estejam separados entre si por distâncias inferiores a quinhentos metros, a APP abrangerá o conjunto de morros ou montanhas, delimitada a partir da curva de nível correspondente a dois terços da altura em relação à base do morro ou montanha de menor altura do conjunto. Foi utilizada a metodologia de Hott et al. (2004) da EMBRAPA, baseado em geotecnologia, aplicando rigorosamente a legislação e adotando um critério na delimitação das elevações por meio do fluxo numérico presente na superfície modelada digitalmente. As etapas necessárias para a elaboração das APPs de topo de morro são mostradas na Figura 2.

Cerne, Lavras, v. 17, n. 4, p. 563-571, out./dez. 2011 


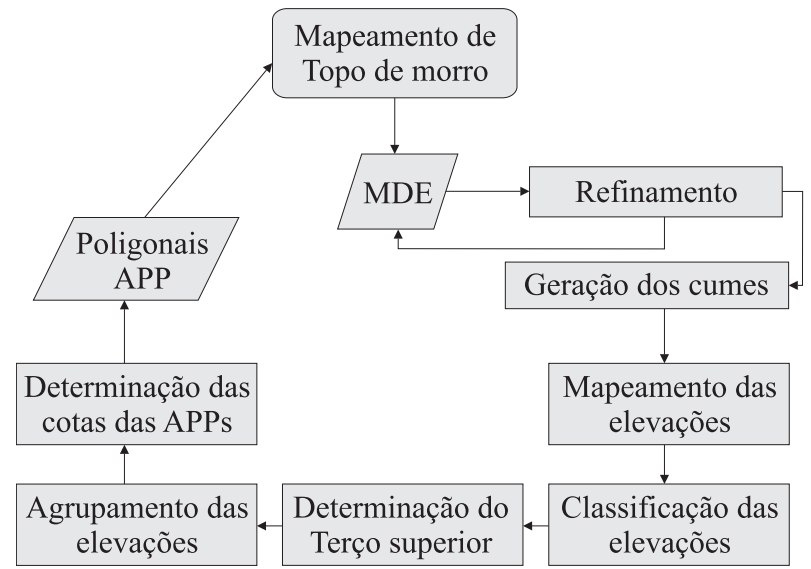

Fonte: Louzada et al. (2009c)

Figura 2 - Fluxograma das etapas desenvolvidas na determinação de APPs de topo de morro.

Figure 2-Flowchart of the stages developed in the determination of APPs of hill top.

\subsubsection{Delimitação das APPs ao longo dos cursos d'água}

Os cursos d'água foram digitalizados em tela, por meio de digitalização visual, utilizando como base a aerofoto ortorretificadas do ano de 2007 na escala 1:35.000 cedidas pelo Instituto Estadual de Meio Ambiente e Recursos Hídricos do Espírito Santo - IEMA (1 m de resolução espacial) e imagens do satélite $\operatorname{GEOEYE~}(0,5$ $m$ de resolução espacial) cedida pela Prefeitura Municipal de Alegre- ES, ajustadas à rede hidrográfica da carta do IBGE de 1:50.000 disponibilizada pela Sistema Integrado de Bases Georreferenciadas do Estado do Espírito Santo - Geobase.

As imagens de satélite utilizadas abrangem duas faixas do município nos seguintes distritos: AlegreSede, Celina e Rive, e São João do Norte, Araraí e Santa Angélica. Em razão de essas imagens não abrangerem todo o município, foram utilizadas as aerofotos nas demais áreas. $\mathrm{O}$ uso dessas duas bases não prejudica os dados pois, de acordo com Peluzio (2010), ao comparar a fotointerpretação em tela, para uma mesma área de estudo, realizada na escala de 1:2.000, sobre imagem aerofotogramétrica (cenário 1) e imagem do satélite GEOEYE, (cenário 2), não foi observada diferença significativa entre as fotointerpretações realizadas, sendo comprovada pelo índice kappa (IK), exatidão global e teste $\mathrm{T}$.

A delimitação das áreas de preservação ao longo dos cursos d'água foi realizada por meio do comando
BUFFER, disponível no módulo Arc Toolbox do programa ArcGIS 9.3, delimitando-se uma área de preservação de $30 \mathrm{~m}$ em cursos d'água com menos de $10 \mathrm{~m}$ de largura e de $50 \mathrm{~m}$ em cursos d'água com largura entre 10 e $50 \mathrm{~m}$.

\subsubsection{Delimitação das APPs ao redor das nascentes}

Nessa etapa, as nascentes foram extraídas a partir dos cursos d'água, considerando que em cada extremidade há uma nascente. A delimitação das áreas de preservação no entorno das nascentes foi realizada por meio do comando BUFFER, disponível no módulo Arc Toolbox do programa ArcGIS 9.3, delimitando-se um raio de preservação de 50 metros no entorno das nascentes.

2.3.4 Delimitação das APPs em encostas com declividades acima de $45^{\circ}$

Nessa etapa, de posse do MDEHC, inicialmente, foi elaborado o mapa matricial de declividade da área de estudo utilizando o comando SLOPE, disponível no módulo Arc Toolbox do programa ArcGIS 9.3. Posteriormente, realizou-se a reclassificação do mapa de declividade com o objetivo de delimitar apenas a classe de APP superior a $45^{\circ}$.

\section{RESULTADOS E DISCUSSÃO}

As áreas do entorno das nascentes apresentam suma importância no que diz respeito à vida útil dos rios por ela abastecido, uma vez que, sem a proteção adequada em torno da mesma, nota-se um processo de degradação do rio por ela abastecido, o que foi verificado em visitas técnicas na área de estudo, indo ao encontro do verificado por Donadio et al. (2005), os quais estudaram quatro nascentes, sendo duas com a presença de vegetação natural remanescente e duas com predominância de atividades agrícolas e concluíram que a presença de remanescentes de vegetação de mata ciliar, auxilia na proteção dos recursos hídricos.

A área ocupada por essas APPs é de $9,87 \mathrm{~km}^{2}$, o que representa 1,28\% da área total do município (Figura 3).

Em decorrência da natureza do relevo, no município de Alegre predominam os rios de planalto, que apresentam rupturas de declive, vales encaixados, entre outras características, que lhes conferem um alto potencial para a geração de energia elétrica. Pelo seu perfil não regularizado, os rios ficam prejudicados no que diz respeito à navegabilidade. Sendo parte integrante da bacia hidrográfica do Rio Itapemirim, os rios do município são classificados como dendrítico, o que é típico de áreas cobertas por rochas sedimentares horizontais. 


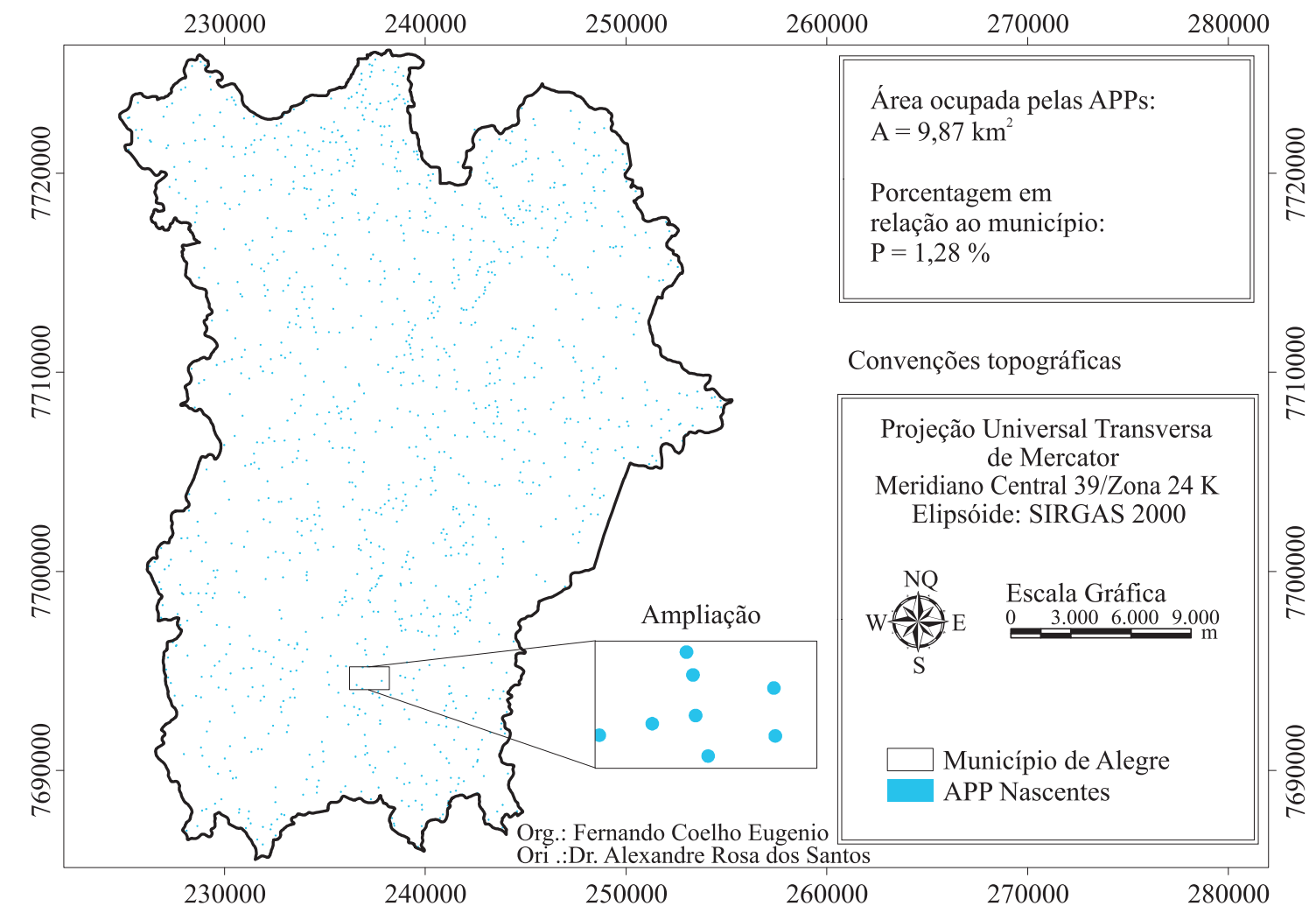

Figura 3 - Total das APPs de Nascentes do município de Alegre.

Figure 3 - Total of APPs of spring the county of Alegre.

As APPs ao longo de curso d'água garantem a estabilização das margens tendo assim, uma importância vital no controle da erosão do solo e da qualidade da água, evitando o carreamento direto para o ambiente aquático de sedimentos, nutrientes e produtos químicos provenientes das partes mais altas do terreno, os quais afetam a qualidade da água, diminuem a vida útil dos reservatórios, das instalações hidroelétricas e dos sistemas de irrigação. A área ocupada pelas APPs de curso d'água representa $12.30 \%$ de todo o município, totalizando 95,11 $\mathrm{km}^{2}$, cujas delimitações são mostradas na Figura 4.

O município de Alegre possui um território que, pela sua formação geológica, é modelado em rochas cristalinas e, portanto, bastante acidentado e elevado, possuindo altitudes que variam de 120 a 1.320 metros. A área ocupada pelas APPs de declividade abrange 1,16\% de todo o município, totalizando $8,99 \mathrm{~km}^{2}$, cujas delimitações são mostradas na Figura 5.

Em razão de seu relevo acidentado, o município de Alegre possui uma extensa área ocupada pelas APPs de Topo de Morro. Em tais áreas verifica-se a importância de ser protegida, uma vez que sendo instrumentos de relevante interesse ambiental elas integram o desenvolvimento sustentável do município visando gerações futuras.

A área ocupada por essas APPs é de 237,35 km², o que representa $30,69 \%$ da área total do município, cujas delimitações são mostradas na Figura 6.

A metodologia de delimitação automática das APPs tendo como referência legal a resolução $n^{\circ}$ 303/2002 do CONAMA (2002) possibilitou identificar e quantificar as categorias de APPs situadas no terço superior dos morros - APP-1, nas nascentes e suas respectivas áreas de contribuição - APP-2, ao longo das margens cursos d'águas - APP-3 e nas encostas com declividade superior a 45 graus - APP-4 (Figura 7 e Tabela 1). Os resultados mostram que a menor e a maior participação entre as categorias de APPs correspondeu às APP-4 e APP-1 com $8,99 \mathrm{~km}^{2}(1,16 \%)$ e $237,35 \mathrm{~km}^{2}(30,69 \%)$, respectivamente.

Cerne, Lavras, v. 17, n. 4, p. 563-571, out./dez. 2011 


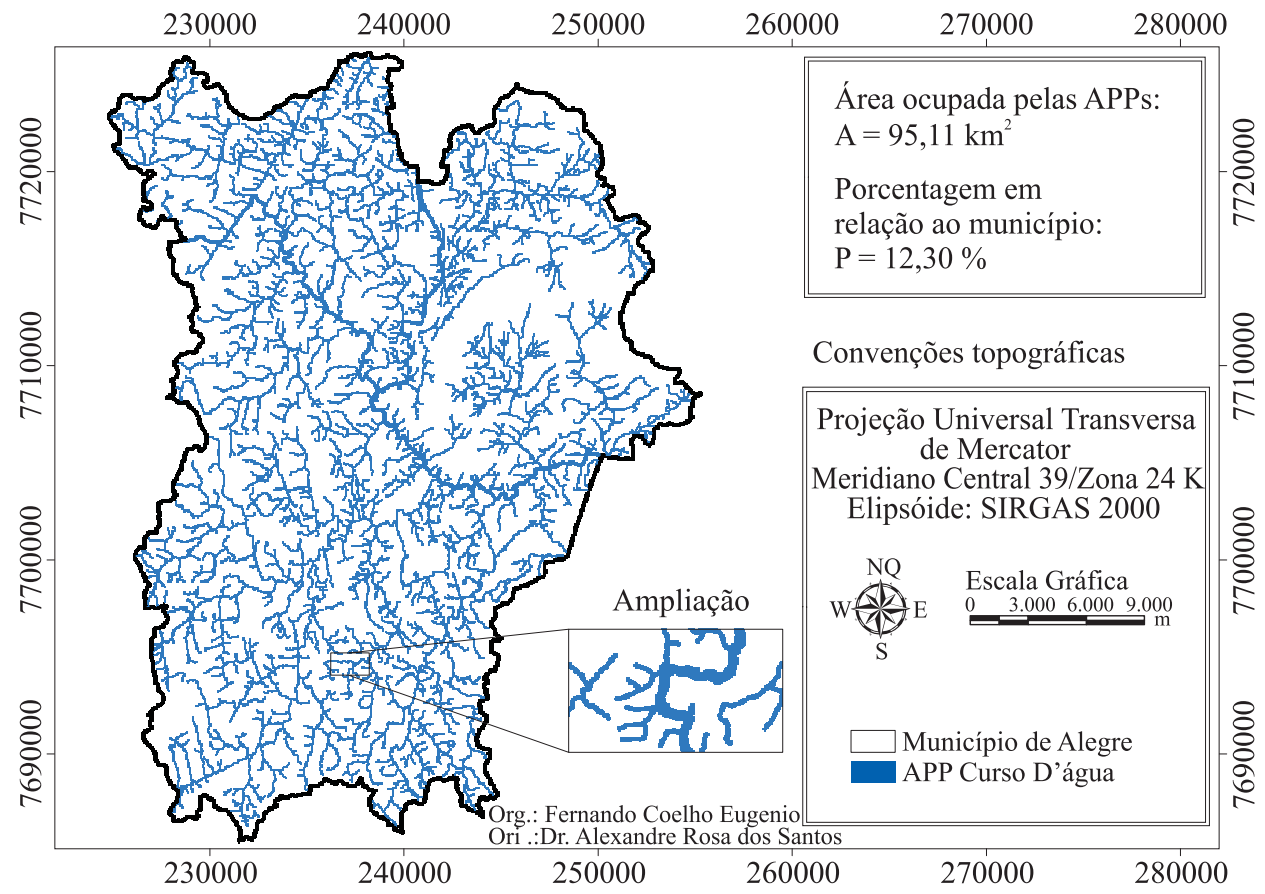

Figura 4 - Total das APPs de Cursos D’água do município de Alegre.

Figure 4 - Total of APPs of Courses of water of the county Alegre.

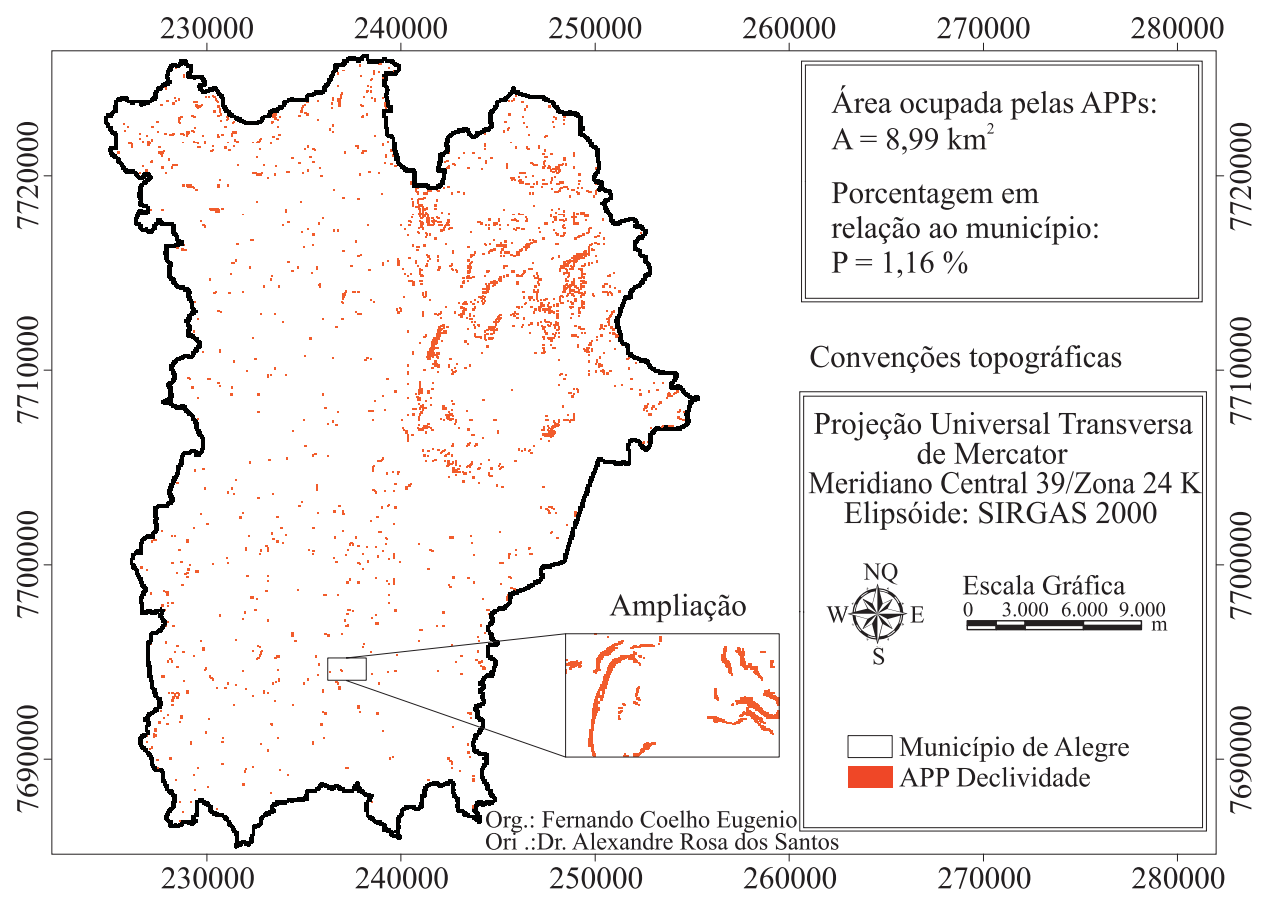

Figura 5 - Total das APPs em encostas com declividades acima de $45^{\circ}$ do município de Alegre.

Figure 5 - Total of APPs in the hillsides with superior steepness to 45 degrees of the county Alegre.

Cerne, Lavras, v. 17, n. 4, p. 563-571, out./dez. 2011 


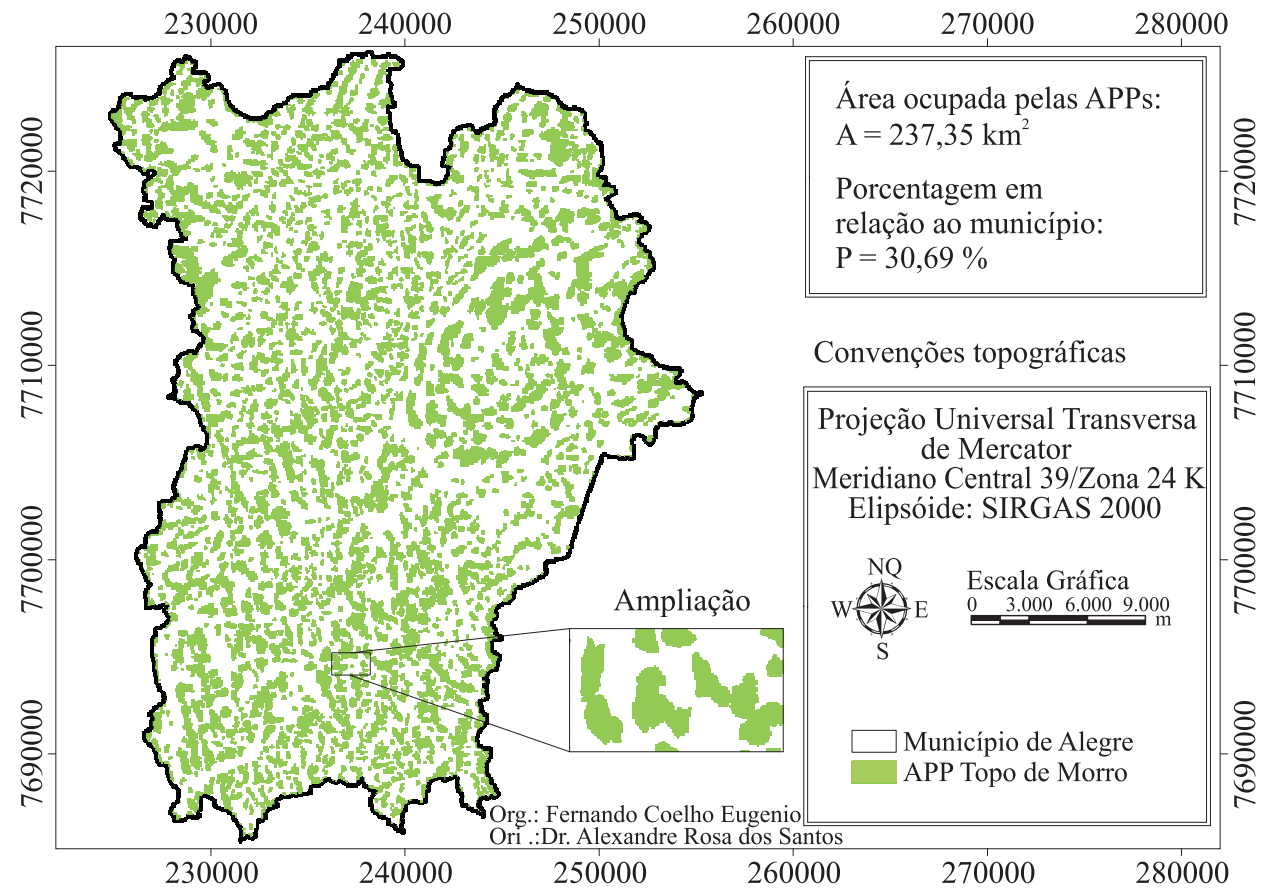

Figura 6 - Total das APPs de topo de morro da município de Alegre.

Figure 6 - Total of APPs of Hill top of the county Alegre.

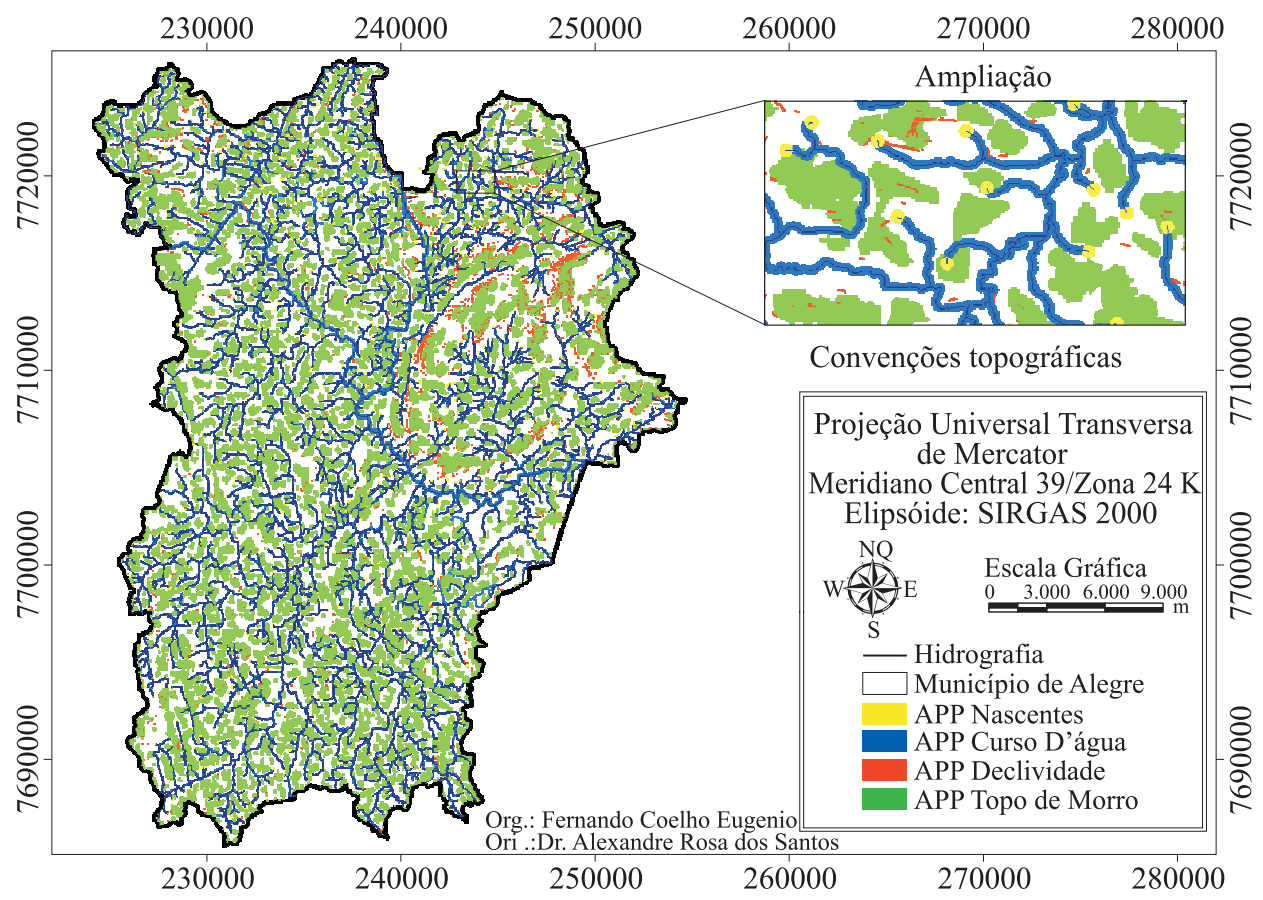

Figura 7 - Total das APPs do município de Alegre-ES.

Figure 7 - Total of the APPs of the county Alegre-ES.

Cerne, Lavras, v. 17, n. 4, p. 563-571, out./dez. 2011 
Tabela 1 - Porcentagem das áreas ocupadas pelas APPs no município de Alegre.

Table 1 - Percentage of the busy areas for APPs in the county of Alegre.

\begin{tabular}{lccc}
\hline APPs & Característica & $\begin{array}{c}\text { Área } \\
\left(\mathrm{Km}^{2}\right)\end{array}$ & $\begin{array}{c}\text { \% ocupada } \\
\text { na área do } \\
\text { município }\end{array}$ \\
\hline APP-1 & Terço superior de morro & 237,35 & 30,69 \\
APP-2 & Raio de 50m & 9,86 & 1,27 \\
APP-3 & Buffer de 30 ou 50m & 95,11 & 12,30 \\
APP-4 & Acima de 45 & 8,99 & 1,16 \\
\hline Total & Sem sobreposições & 336,39 & 43,50 \\
\hline
\end{tabular}

Nota-se ainda que as APPs ocupam uma área total de $336,39 \mathrm{~km}^{2}$, de um total de $773,40 \mathrm{~km}^{2}$ da área do município, representando $43,50 \%$ de áreas que devem ser protegidas legalmente. O percentual de APPs delimitadas neste município está dentro de um percentual médio de APPs encontrado em outros estudos de regiões montanhosas, como: Nascimento et al. (2005) na bacia hidrográfica do rio Alegre $\left(208,2 \mathrm{~km}^{2}\right)$, bacia situada no município de Alegre-ES, Louzada (2010) na região dos Parques Estaduais Forno Grande e Pedra Azul-ES, região serrana, área delimitada como Corredor Ecológico Forno Grande-Pedra Azul, Oliveira et al. (2008) nos municípios de Alto Jequitibá, Alto Caparaó e Ervália, Louzada et al. (2009b) na bacia hidrográfica do ribeirão Estrela do Norte, município de Castelo-ES, que encontraram respectivamente, $45,95 \%, 45,9 \%, 48,1 \%$ e $41,1 \%$ das áreas identificadas como de preservação.

\section{CONCLUSÕES}

A metodologia adotada para delimitação automática das APPs mostrou-se eficiente, produzindo de forma eficaz e rápida informações precisas sobre as suas dimensões e distribuição espacial no município, sendo esta uma ferramenta de auxilio na tomada de decisões que contribui para o entendimento dos processos futuros de ocupação da terra.

\section{REFERÊNCIAS}

ARES. Atlas das áreas com potencial de riscos do Estado do Espírito Santo. Vitória: Imprensa Estadual, 2006. 125 p.

CONSELHO NACIONAL DO MEIO AMBIENTE.

Resolução no 303, de 20 de março de 2002. Dispõe sobre

Cerne, Lavras, v. 17, n. 4, p. 563-571, out./dez. 2011 parâmetros, definições e limites de Áreas de Preservação Permanente. Brasília, 2002. Disponível em: <http://www. mma.gov.br $>$. Acesso em: 5 abr. 2008.

DONADIO, N. M. M.; GALBIATTI, J. A.; PAULA, R. C. Qualidade da água de nascentes com diferentes usos do solo na bacia hidrográfica do córrego rico, São Paulo, Brasil.

Engenharia Agrícola, Jaboticabal, v. 25, n. 1, p. 23-27, 2005.

GARCIA, M. J. L.; CAMARASA, A. M. Use of geomorphological units to improve drainage network extraction from DEM: comparision between automated extraction and photointerpretation methods in the Carraixet catchment, Valencia, Spain. JAG, n. 3/4, p. 187-194, 1999.

HOTT, M. C.; GUIMARÃES, M.; MIRANDA, E. E. de. Método para a determinação automática de áreas de preservação permanente em topos de morros para o Estado de São Paulo, com base em geoprocessamento. Campinas: Embrapa Monitoramento por Satélites, 2004. 32 p. (Documentos, 34).

LOUZADA, F. L. R. de O. Análise das áreas de preservação permanente da bacia hidrográfica do ribeirão Estrela do Norte, ES. 2008. Monografia (Especialização em Educação Ambiental e Recursos Naturais) - Faculdade de Filosofia Ciências e Letras de Alegre, Alegre, 2008.

LOUZADA, F. L. R. de O. Proposta de corredores ecológicos para interligação dos Parques Estaduais de Forno Grande e PEDRA Azul, ES, utilizando geotecnologia. 2010. Dissertação (Mestrado em Ciências Florestais) - Universidade Federal do Espírito Santo, Alegre, 2010 .

LOUZADA, F. L. R. de O.; SANTOS, A. R.; MARINHO, C. C.; SATLER, M. A. Delimitação automática das áreas de preservação permanentes da bacia hidrográfica do ribeirão Estrela do Norte, ES. In: ENCONTRO LATINO AMERICANO DE PÓS-GRADUAÇÃO, 9., 2009, São José dos Campos. Anais... São José dos Campos: UNIVAP, 2009a. CD-ROM.

LOUZADA, F. L. R. de O.; SANTOS, A. R.; SATTLER, M. A. Análise das áreas de preservação permanentes da bacia hidrográfica do ribeirão Estrela do Norte, ES. Revista de Biologia e Saúde, Curitiba, v. 3, n. 2, p. 128-141, jul./dez. 2009b. 
LOUZADA, F. L. R. de O.; VIEIRA, M. V. M.; PELUZIO, T. M. O.; SAITO, N. S.; SOUZA, S. M.; SANTOS, A. R. Uso de Geotecnologia na determinação de áreas de preservação permanente em topos de morros na micro-região de planejamento da Central Serrana, ES. In: ENCONTRO LATINO AMERICANO DE PÓS-GRADUAÇÃO, 9., 2009, São José dos Campos. Anais... São José dos Campos: UNIVAP, 2009c. CD-ROM.

NASCIMENTO, M. C.; SOARES, V. P.; RIBEIRO, C. A. A. S.; SILVA, E. Uso do geoprocessamento na identificação de conflito de uso da terra em áreas de preservação permanente Bacia Hidrográfica do Rio Alegre, Espírito Santo. Ciência Florestal, Santa Maria, v. 15, n. 2, p. 207-220, 2005.

OLIVEIRA, F. S.; SOARES, V. P.; PEZZOPANE, J. E. M.; GLERIANI, J. M.; LIMA, G. S.; SILVA, E.; RIBEIRO, C. A. A. S.; OLIVEIRA, A. M. S. Identificação de conflito de uso da terra em Áreas de preservação permanente no entorno do parque nacional do Caparaó, Estado de Minas Gerais. Revista Árvore, Viçosa, v. 32, n. 5, p. 899-908, 2008.

OLIVEIRA, M. J. Proposta metodológica para delimitação automática de áreas de preservação permanente em topos de morro e em linha de cumeada. 2002. 53 p. Dissertação (Mestrado em Ciência Florestal) - Universidade Federal de Viçosa, Viçosa, 2002.

PELUZIO, T. M. de O. Imagens aerofotogramétricas e orbitais na determinação do uso e de ocupação do solo e Áreas de Preservação Permanente (APPs). 2010.

Dissertação (Mestrado em Ciências Florestais) - Universidade Federal do Espírito Santo, Vitória, 2010.

TRIBE, A. Automated recognition of valley lines and drainage networks from grid digital elevation models: a review and a new method. Journal of Hidrology, Amsterdam, v. 139, p. 263-293, 1992.

Cerne, Lavras, v. 17, n. 4, p. 563-571, out./dez. 2011 
